\title{
Determinants of Volatility of the Derivative Financial Instrument in Ukraine
}

\author{
Oleksandr M. Petruk ${ }^{1, *}$, Oksana S. Novak ${ }^{1}$, Anastasiia O. Petruk ${ }^{1}$, Nataliia H. Radchenko ${ }^{2}$ \\ ${ }^{1}$ Department of Finance and Crediting, Zhytomyr Polytechnic State University, 10005, Zhytomyr, Ukraine \\ ${ }^{2}$ Department of Finance, Banking and Insurance, Dmytro Motornyi Tavria State Agrotechnological University, 72312, Melitopol, \\ Ukraine
}

Received April 16, 2021; Revised June 15, 2021; Accepted June 24, 2021

\section{Cite This Paper in the following Citation Styles}

(a): [1] Oleksandr M. Petruk, Oksana S. Novak, Anastasiia O. Petruk, Nataliia H. Radchenko, "Determinants of Volatility of the Derivative Financial Instrument in Ukraine" Universal Journal of Accounting and Finance, Vol. 9, No. 4, pp. 653-666, 2021. DOI: 10.13189/ujaf.2021.090412.

(b): Oleksandr M. Petruk, Oksana S. Novak, Anastasiia O. Petruk, Nataliia H. Radchenko (2021). Determinants of Volatility of the Derivative Financial Instrument in Ukraine. Universal Journal of Accounting and Finance, 9(4), 653-666. DOI: 10.13189/ujaf.2021.090412.

Copyright $\bigcirc 2021$ by authors, all rights reserved. Authors agree that this article remains permanently open access under the terms of the Creative Commons Attribution License 4.0 International License

\begin{abstract}
The article discusses empirical calculations of sustainable development and volatility of derivative financial instruments in the banking system. The methodical approach to forecasting the index of the first stock trading system (FSTS) for sustainable market development is presented, considering the lack of normal distribution of financial resources in the banking system. It is substantiated that when choosing the volatility model and setting the option price, it is important to consider the theoretical generality and composition of the volatility structure, which is able to effectively and accurately estimate the parameters. It is proved that the rate of average volatility variable for modeling, analysis and stable assessment of important market parameters (i.e., local volatility) is determined using the moments of past periods. The real and forecast value of FSTS volatility at different values of the model parameter is developed. A model of implied volatility for the FSTS index is built. It is substantiated that the formulation of stable market development of derivative financial instruments takes into account all its semantic and financial features of resisting the influence of external and internal factors (shocks, imbalances) and maintaining dynamic equilibrium to ensure parameters of the entire financial system needed to form positive feedback between financial and real sector of the economy. The ratio of world GDP and the nominal value of derivative financial instruments were estimated. Maps of the market value of over-the-counter DFI, gross risk exposure in the over-the-counter DFI market and the
\end{abstract}

nominal value of exchange-traded PFI are presented. The factor models of influence on the development of the exchange-traded and over-the-counter PFI market of world and national levels are constructed.

Keywords Derivative Financial Instruments, Volatility, Banking System, Index Options, Stock Market, Market Risks

\section{Introduction}

The intensification of globalization processes, the acceleration of capital flows, and the deepening of crisis phenomena increase the need to taking into the account the development of derivative financial instruments in the global financial architecture. At the same time, the extent and depth of the recession in the financial sector confirms the possibility of crises in the derivatives market and demonstrates the need to monitor its condition to stop the spread of the chain "infection effect" of the banking system in the international financial space. This chain provokes an imbalance in the reproduction of the structure of the economy, diagnosing violations of the financial stability of the state in the current and long term.

Assessing the impact of derivative financial instruments at both the micro and macro levels is ambivalent, and its application significantly increases the risk management 
opportunities for stock market participants, and thus can determine the volume and diversity of their financial transactions with extrapolation to economic growth and welfare of some countries. However, their complex, multilevel and risky use, in the absence of appropriate rules and control by regulators at the national and international levels, leads to increased turbulence in financial markets. Therefore, the dynamic development of innovative financial instruments is complex, which is determined by external factors arising from the imperfection of stock markets and the turbulence of the macroeconomic environment, and internal factors, the source of which is the need for stock market participants to create instruments that will mitigate the risks, increase profits and its competitiveness. Therefore, an integral element of the financial sector is the derivatives market, the main task of which is to hedge the risks that accompany transactions with derivative financial instruments. In this case, one of the main parameters that characterize transactions with derivatives is volatility.

Theoretical and methodological principles of derivative financial instruments (DFI) market organization are considered in the works of such scientists as Ayadi [1], H. Cao [2], D. Chance [3], A. Chisholm [4], M. Darby [5], R. Davies [6]. Thorough research of the DFI market was conducted by such scientists as: D. Duffie [7], R Ferstl and D. Seres [8], J. Foster [9], J. Frankel and A. Rose [10].The study of the DFI market is closely related to the progressive, sustainable development of the entire financial market, and the stability of the banking system which is widely covered in the works by H. Jo, C. Lee, A. Munguia and C. Nguyen [11], J. Hull [12], A. Litvinova [13], G. Nwaovi [14], M. Rubinstein [15], G. L. Kaminsky and C. M. Reinhart [16], L. Laeven and F. Valencia [17], A. Demirguc-Kunt and E. Detragiache [18; 19], I. Britchenko and T. Cherniavska [20]. However, the issues of forming an analytical basis for monitoring the financial stability of the banking system and developing its diagnostic tools for the functioning of the banking system and its structural elements in the DFI market remain insufficiently addressed. Therefore, the priority of this study is the implementation of empirical calculations of volatility of derivative financial instruments based on the model of forecasting the index of the first stock trading system (FSTS) for sustainable market development, given the lack of normal distribution of financial resources in the banking system.

\section{Analysis of Models of Volatility}

The relationship between volatility and asset can be explained by the level of volatility depending on the model (CEV) of variation of constant elasticity [21-23], or the model of Cox and Ross [24]. Stochastic volatility can also occur endogenously through equilibrium, which simulates the behavior of market participants. More general stochastic models of volatility are proposed by Hull and White [25], based on the idea that the correct specification of volatility can have a general and analytical interpretation. Very often, the use of plausible parameters, as in the case of a negative correlation between volatility and price, does not correspond in practice to the actual option prices. Empirical verification is a search for structural parameters by selecting different time series for evaluation [26;27].

When choosing a model of volatility and setting the option price, you need to take into account the theoretical generality and composition of the structure of volatility, which can effectively and accurately assess the parameters [28; 29]. The rate of average volatility variable for modeling, analysis and stable assessment of important market parameters (i.e., local volatility) is determined using the moments of past periods. The calculation algorithm (1):

$$
Z_{t}=\operatorname{Ln}\left(e^{-r t} P_{t}\right)
$$

when discounting a variable (i.e., stock prices) is determined by a branched order function (2) [30]:

$$
S_{t}^{(m)}=\lambda \int_{0}^{\infty} e^{-\lambda u}\left(Z_{t}-Z_{t-u}\right)^{u} d u
$$

where: $\lambda-$ is a parameter that describes the weight of retrospective observations. Stock prices satisfy the stochastic differential equation (3):

$$
d Z_{t}=\sigma\left(t, Z, S_{t}^{(1)}, \ldots, S_{t}^{(n)}\right) d B_{t}+\mu\left(t, Z, S_{t}^{(1)}, \ldots, S_{t}^{(n)}\right) d t
$$

for the smoothing functions $\sigma(\cdot) \geq 0 \mathrm{i} \mu(\cdot)$. Since $\sigma(\cdot) \geq$ 0maydependon $P_{t}$, the model includes a partial case where volatility is a determined function of price [29]. The authors suppose that instantaneous volatility is a function of the first ordinal branch (4):

$$
S_{t}=S_{t}^{(1)}
$$

This makes it possible to obtain a correct formulation of the Cauchy problem for the stochastic differentiated Kolmogorov equation and to solve it with maximum accuracy according to the Hobson-Rogers model. Using equation (2) is decomposed $\mathrm{S}_{t}$ as the deviation of the current price from the exponentially weighted average of past prices (5):

$$
S_{t}=Z_{t}-\lambda \int_{0}^{\infty} e^{-\lambda u} Z_{t-u} d u
$$

The parameter $\lambda$ determines the time horizon of the "moving time windows" of the integral. For large values of the parameter $\lambda$, the current price $S_{t}$ depends on the previous period, while for smaller values $-S_{t}$ coincide with the increase of the variable value on the price [31; 32]. In this case, the level of dependence of volatility is more consistent. To build the basic model used for computational procedures, the authors consider the neutral risk limit $\bar{P}$ and $\bar{P}-$ Brownian motion $B_{t}$. Let $e^{-r t} P_{t}$ be - 
martingale, which allows determining the stochastic equation $d \bar{P}_{t}=\sigma \bar{P}_{t} d \bar{B}_{t}$, by the formula (6):

$$
d Z_{t}=\sigma d \bar{B}_{t}-\frac{1}{2} \sigma^{2} d t
$$

After replacing $u=t-s$ equation (5) has the form (7):

$$
S_{t}=Z_{t}-\lambda e^{-\lambda t} \int_{-\infty}^{t} e^{-\lambda s} Z_{s} d s
$$

The differential of it is equal to (8):

$$
d S_{t}=d Z_{t}-\lambda S_{t} d t
$$

The general formula for the differential of functions of higher order branches $\left(Z_{t}, S_{t}^{(1)}, \ldots, S_{t}^{(n)}\right)$, forms the Markov process. Having made a replacement (9):

$$
U=Z-S
$$

and marked $f\left(t, U_{t}, Z_{t}\right)$ the price at the moment $t \leq T$, the authors get the cost of a possible premium that has the form in time $T(10)$ :

$$
f\left(t, U_{T}, Z_{T}\right)=q\left(Z_{T}\right)
$$

The authors obtain a differential equation in partial derivatives with a limit in equation (11):

$$
f_{t}+\lambda(Z-U) f_{U}-\frac{1}{2} \sigma(Z-U)^{2}\left(f_{Z Z}-f_{Z}\right)=0
$$

Equation (11) is an ultra-parabolic stochastic equation of the Kolmogorov type. Now the authors suppose that volatility changes over time. The nature of this process is a problem in financial theory because the relationship between volatility and past price changes is intuitive [33]. To predict volatility, it is proposed to link it with past changes. This hypothesis introduces the effect of volatility accumulation. Depending on the values $\lambda$, the variables of the price for equation (11) change significantly over a time. Peculiarities of volatility dynamics (local constancy and dependence of volatility on the observed dynamics) are explained by its nature.

Using the value of the FSTS index value the value of the function $\mathrm{S}(12)$ :

$$
\bar{S}_{t}=\sum_{i=0}^{M} \frac{U_{i}}{[I]}\left(Z_{t}-Z_{t-i}\right)
$$

where, $U_{i}=e^{-\lambda i \Delta t}$ weight coefficients, and $[I]-$ their sum. To assess volatility, the authors use formula (13):

$$
: \bar{\sigma}=\sqrt{k \sum_{i=1}^{M} \frac{U_{i}}{[I]}\left(Z_{t-i+1}-Z_{t-i}-\bar{\mu}_{t}\right)^{2}},
$$

where (14):

$$
\bar{\mu}_{t}=\operatorname{Ln} \frac{M-t}{t}
$$

is the weighting factor (15):

$$
k=[I]^{2} / \Sigma\left(\frac{[]^{2}}{M}-U_{i}^{2}\right)
$$

correction factor for unbiased assessment $\sigma^{2}$.

For an example of calculating daily estimates, 122 operational days of 2019 and a unit of time $\Delta t=1 / 122$ were considered. Taking $M=1224$, the authors consistently evaluate the observations for each of the operating days, according to formulas (12) and (13). Figure 1 shows the relationship between the estimate (12) and volatility (13) for different values $\lambda$. Each case illustrates the curve obtained by the volatility approximation $\sigma_{t}$ using a second-order polynomial $a \bar{S}^{2}+b \bar{S}+c$.

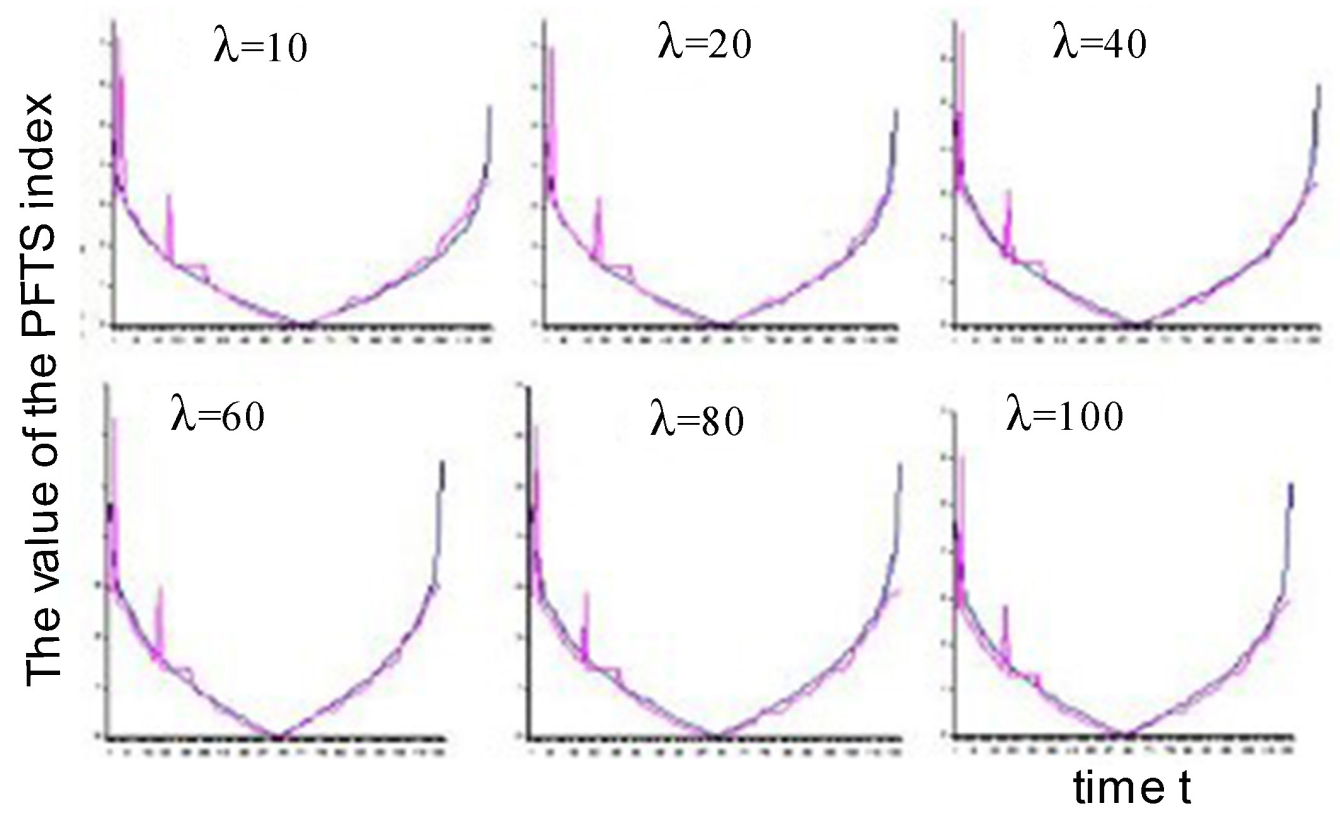

Figure 1. Real and forecast value of FSTS index volatility at different values of the parameter $\lambda=60$ 


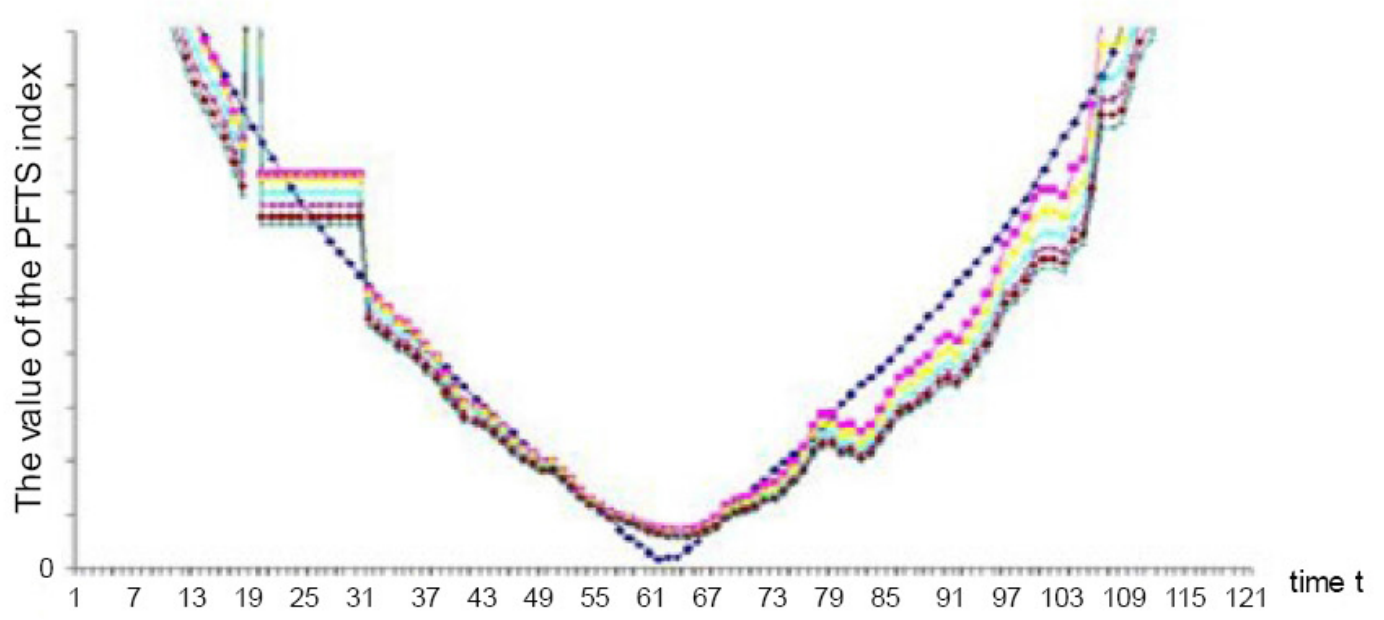

empirical value

Fraction $\lambda=60$

$$
\begin{aligned}
& \text { Fraction } \quad z=10 \\
& \text { Fraction } z=80
\end{aligned}
$$$$
\text { Fraction }
$$$$
\text { Fraction } \quad Z=100
$$

Fraction $\lambda=40$

Figure 2. Trend of volatility of the FSTS index, found as a fraction of two polynomials at different values of the parameter $\lambda$

\begin{tabular}{|c|c|c|c|c|c|c|}
\hline & 10 & 20 & 40 & 60 & 80 & 100 \\
\hline Coefficient & \multicolumn{6}{|c|}{$\sigma(S)=\frac{1+a S+b S^{2}}{c+d S+e S^{2}}$} \\
\hline $\mathrm{c}$ & 0.278 & 0.282 & 0.295 & 0.306 & 0.315 & 0.323 \\
\hline d & -0.035 & -0.035 & -0.036 & -0.038 & -0.039 & -0.040 \\
\hline $\mathrm{e}$ & -0.003 & -0.003 & 0.003 & -0.003 & 0.003 & -0.003 \\
\hline $\mathrm{a}$ & 0.241 & 0.240 & 0.239 & 0.238 & 0.238 & 0.238 \\
\hline $\mathrm{b}$ & 0.015 & 0.015 & 0.015 & 0.015 & 0.015 & 0.015 \\
\hline \multicolumn{7}{|c|}{$\sigma(S)=a S+b$} \\
\hline $\mathrm{a}$ & -0.006 & -0.006 & -0.006 & -0.006 & -0.005 & -0.005 \\
\hline $\mathrm{b}$ & 1.268 & 1.227 & 1.165 & 1.118 & 1.083 & 1.056 \\
\hline \multicolumn{7}{|c|}{$\sigma(S)=a S^{2}+b S+c$} \\
\hline $\mathrm{c}$ & 3.298 & 3.233 & 3.090 & 2.974 & 2.894 & 2.813 \\
\hline d & 0.881 & 0.857 & 0.816 & 0.774 & 0.760 & 0.740 \\
\hline $\mathrm{a}$ & 0.059 & 0.057 & 0.054 & 0.051 & 0.050 & 0.049 \\
\hline \multicolumn{7}{|c|}{$\sigma(S)=\sqrt{a+b S^{2}}$} \\
\hline $\mathrm{a}$ & 268.37 & 263.14 & 251.61 & 242.37 & 235.15 & 229.46 \\
\hline b & -1.772 & -1.727 & -1.646 & -1.584 & -1.536 & -1.499 \\
\hline
\end{tabular}

Table 1. Parameters for different types of models

Figure 2 shows the relationship between the estimate (12) and the volatility $\sigma_{t}$ calculated using the fraction of square trinomials (16):

$$
\sigma(S)=\frac{1+a S+b S^{2}}{c+d S+e S^{2}}
$$

Table 1 shows the parameters for different types of models, with values, calculated using the method of least squares.

The study proves that the most effective specification for the volatility function is $(17 ; 18)$ :

$$
\begin{gathered}
\sigma(S)=\frac{1+a S+b S^{2}}{c+d S+e S^{2}}, \\
\sigma(S)=a S^{2}+b S+c
\end{gathered}
$$

which reduces the calculation effort to determine the problem optimization [30;31]. Empirical assumptions are obvious and prove the existence of the dependence of volatility on branched first-order functions on the example 
of the FSTS index [32]. The quadratic regression, especially the fraction of square trinomials, approximates the volatility function best.

In option pricing theory, the underlying asset simulates a geometric Brownian motion, which is the risk limit that is defined as (19) [33]:

$$
d S_{t}=r S_{t} d t+\sigma S_{t} d W_{t}
$$

where: $r$ - local risk-free interest rate; $\sigma$ - volatility.

Assuming that both parameters are constants, then model (19) describes simple options with variable volatility values, allowing it possible to obtain the price of a regular option that is consistent with the parameters of the variables, and choose the correct strategy to increase hedging performance [34]. In the local volatility model, the variable is a deterministic function of time and the current price of the underlying asset [35], which allows the function to be accurately determined from the variable so that option prices are consistent with market prices. It is proposed to define the model of the variable as the difference between the current price and the weighted average of past prices. If the Brownian motion $\mathrm{W}$ is denoted by the stock market price $\mathrm{S}_{t}$, and by $\mathrm{M}_{t}$ and $\mathrm{D}_{t}$ the corresponding trends and deviations of the processes, then the model can be written as follows (20) [36]:

$$
M_{t}=\lambda e^{-\lambda t} \int_{-\infty}^{t} e^{\lambda s} Z_{s} d s, \lambda \geq 0, D_{t}=Z_{t}-M_{t}
$$

where (21):

$$
Z_{t}=\operatorname{Ln}\left(e^{-r t} S_{t}\right)
$$

is the logarithm of the discount price of the process. Functions $\mathrm{e}^{\lambda} \sin (20)$ are weight coefficients, and parameter $\lambda$ describes the rate at which prices fall. In this case $\mathrm{S}_{t}$ is determined by the stochastic differentiated equation (22) [36]:

$$
d S_{t}=\mu(D) S_{t} d t+\sigma\left(D_{t}\right) S_{t} d W_{t}
$$

where, $\mu$ and $\sigma \geq 0$ are bounded functions that satisfy the formulated hypotheses in order to ensure that the system $(20 ; 22)$ has practical value.

A key feature of the model is that the process $\left(S_{t}, D_{t}\right)$ is of Markov type [31]. Thus, the price $U$ of the maturity option $T$, has the form $(23)[37 ; 38]$ :

$$
\begin{gathered}
U\left(S_{t}, t\right)=e^{-r(T-t)} K w\left(r(T-t)+\operatorname{Ln}\left(S_{t} / K\right),\right. \\
\operatorname{LnK}, T-t)
\end{gathered}
$$

where: $\mathrm{K}$ - the initial option price;

$$
w=w(x, y, t)
$$

formula (24) is the definition of the Cauchy problem (25) [39]:

$$
\begin{gathered}
\frac{\sigma^{2(x-y)}}{2}\left(\partial_{x x} w-\partial_{x} w\right)+(x-y) \lambda \partial_{y} w-\partial_{t} w=0, \text { in } R^{2} \times \\
w(x, y, 0)=\left(e^{x}-1\right) \text { at }(x, y) \in R^{2}
\end{gathered}
$$

Thus, path-dependent models are based on empirically proven hypotheses of the dependence of volatility with respect to deviation. In Figure 3 for FSTS index options, the implied change in the price of the adjusted logarithmic money surface during 2019 is noted [40; 41]. The authors note that the average weight $\lambda \mathrm{e}^{\wedge}(-\lambda t)$ in formula (26) is not flexible enough and does not take into account all the features of the process (for example due to mergers or changes in capitalization). Figure 4 presents the implication of volatility for the FSTS index. The studied variables are grouped by areas, the value of which increases with decreasing $\mathrm{D}_{t}$. This highlights the relationship between variable and market prices.

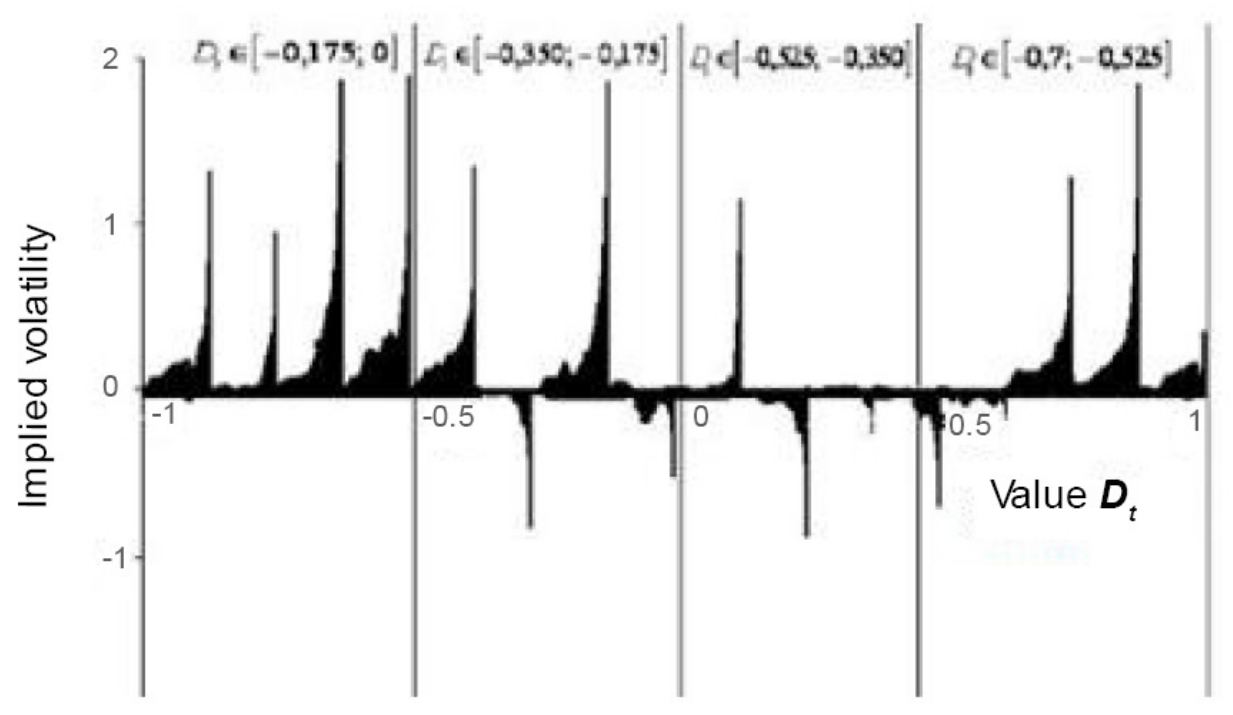

Figure 3. Implied volatility is based on the values of the logarithmic money surface $\frac{\operatorname{Ln}\left(e^{r(T-t)} S_{t} / K\right)}{\sqrt{T-t}}$ on the grouped values of the deviation trend $D_{t}$ for the FSTS index in 2019 


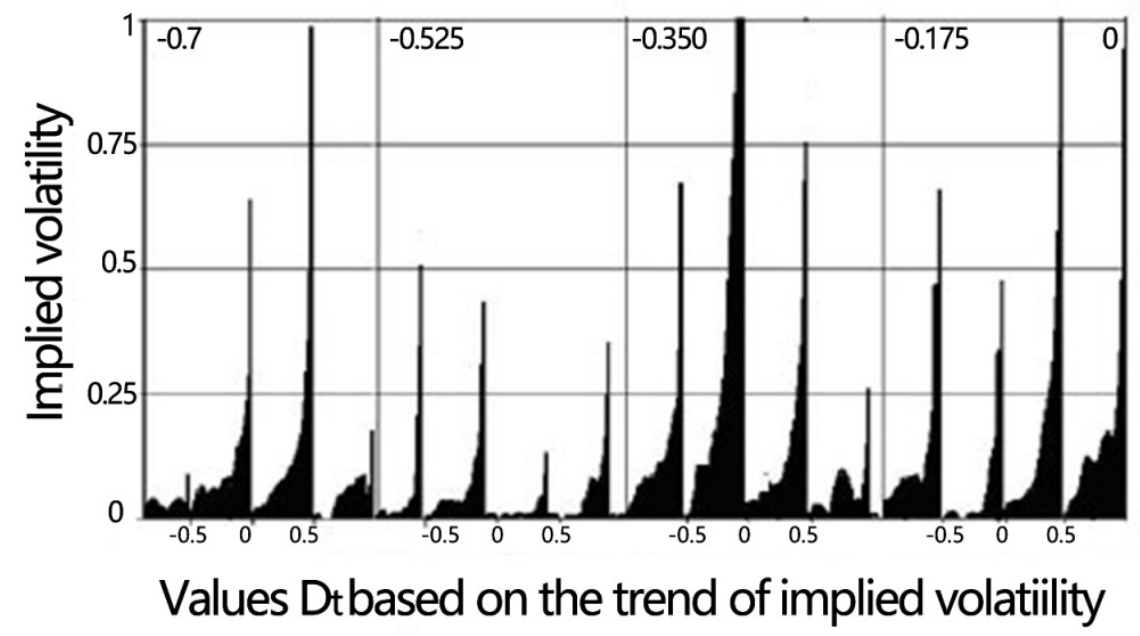

Figure 4. Implied volatility is based on the values of the logarithmic money surface $\frac{\left|\operatorname{Ln}\left(e^{r(T-t)} S_{t} / K\right)\right|}{\sqrt{T-t}}$ on the grouped values of the deviation trend $D_{t}$ for the FSTS index in 2019

Mathematical and economic characteristics of the Hobson-Rogers model in determining the deviation of the process $\mathrm{D}_{t}$, includes the movement of the underlying asset in the past period (i.e., in the interval $(-\infty, \mathrm{T}])$ and requires a limitation of the calculation time with the available data set. It is proposed to generalize the Hobson-Rogers model for asset prices that depend on the variable of the previous period.

The authors consider the average weight as an integrated function $(-\infty, \mathrm{T}]$ that has a positive value $(0, T](27)[42]$ :

$$
F(t)=\int_{-\infty}^{t} \phi(s) d s
$$

The authors note that if $\phi$ has a compact carrier (i.e., a subset of the domain of the function $\phi$, which acquires non-zero values) then the integration domain (27) is limited. The authors denote it by the risk-free rate (28):

$$
B_{i}=e^{r t}
$$

The authors define the process (29) [43]:

$$
\begin{array}{r}
M_{t}=\frac{1}{F(t)} \int_{-\infty}^{t} \phi(s) Z_{s} d s \text { or equivalent } \\
d M_{t}=\frac{\phi(t)}{F(t)}\left(Z_{t}-M_{t}\right) d t
\end{array}
$$

where, $Z_{t}-$ is the solution to the differential equation.

$$
d Z_{t}=\mu\left(Z_{t}-M_{t}\right) d t+\sigma\left(Z_{t}-M_{t}\right) d W_{t}
$$

The authors note that $\mu$ and $\sigma$ - are bounded continuous quantities by the Hölder function and $\sigma$ - is a positive function. The authors assume that the flexible deviation of this process is determined in the period of the total average weight and allows comparing it at the end of the period. That is, the differentiated equation (30), taking into account (29), has a weak calculation algorithm for $(Z, M),(Z, D)$, which embodies the Markov process. Typing of average weight has the following form: $\phi(t)=$ $e^{P(t)} \max \{Q(t), 0\}$, where $P(t), Q(t)$ are polynomial functions, in particular $P(t)=\lambda t$ and $Q(t)=1 ; \phi(t)=$ 1 for $t \in[0, T]$ and $\phi(t)=0$ for $t \notin[0, T]$, which corresponds to the geometric mean Asian option; $\phi(t)-$ linear function - the most common case.

Figure 5 shows the value of the implied volatility for the FSTS index. The studied variables are grouped by areas of deviation values $D(t)$. Thus, the value of implied volatility increases with decreasing $D(t)$. This means that there is a close relationship between variable and market prices. 


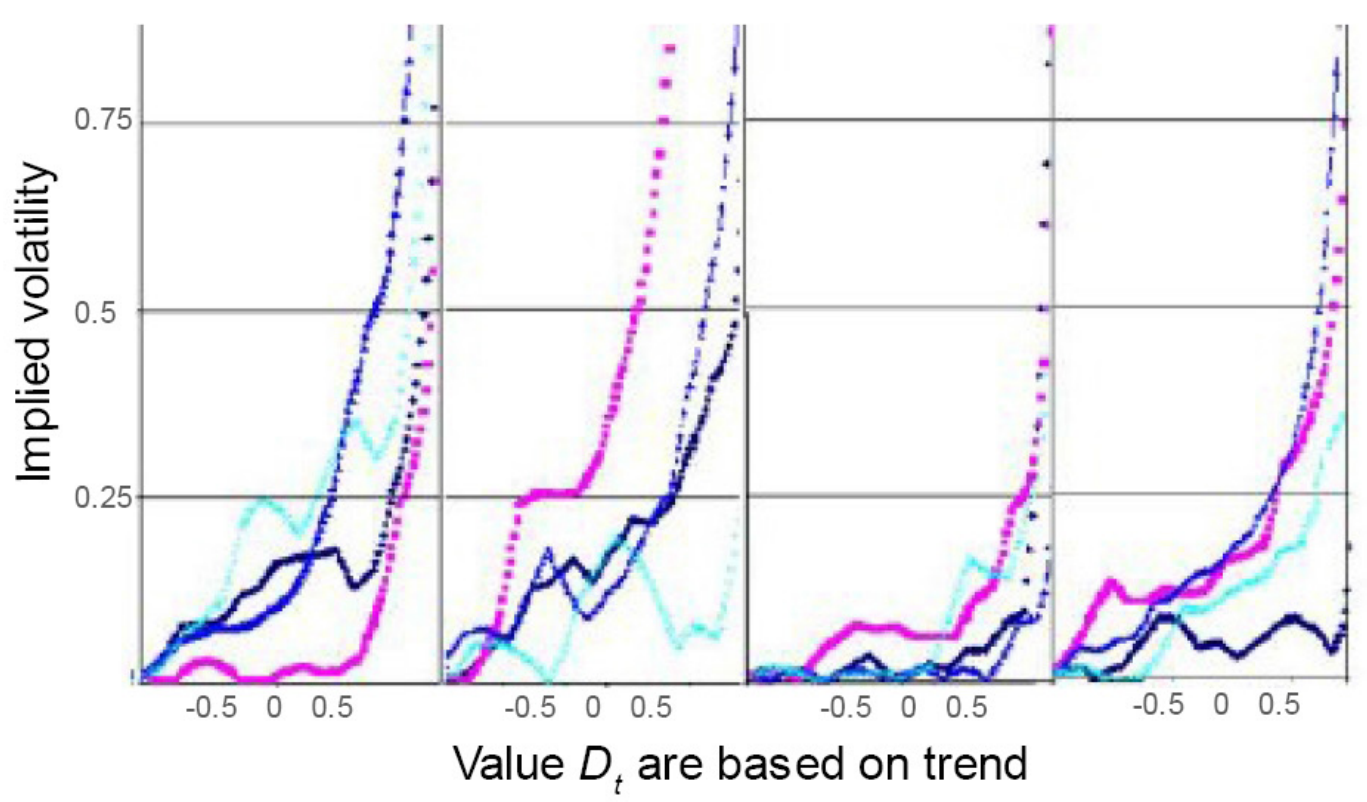

Figure 5. Implied volatility by grouped values of deviation trend $\mathrm{D}_{t}$ for the FSTS index in 2019

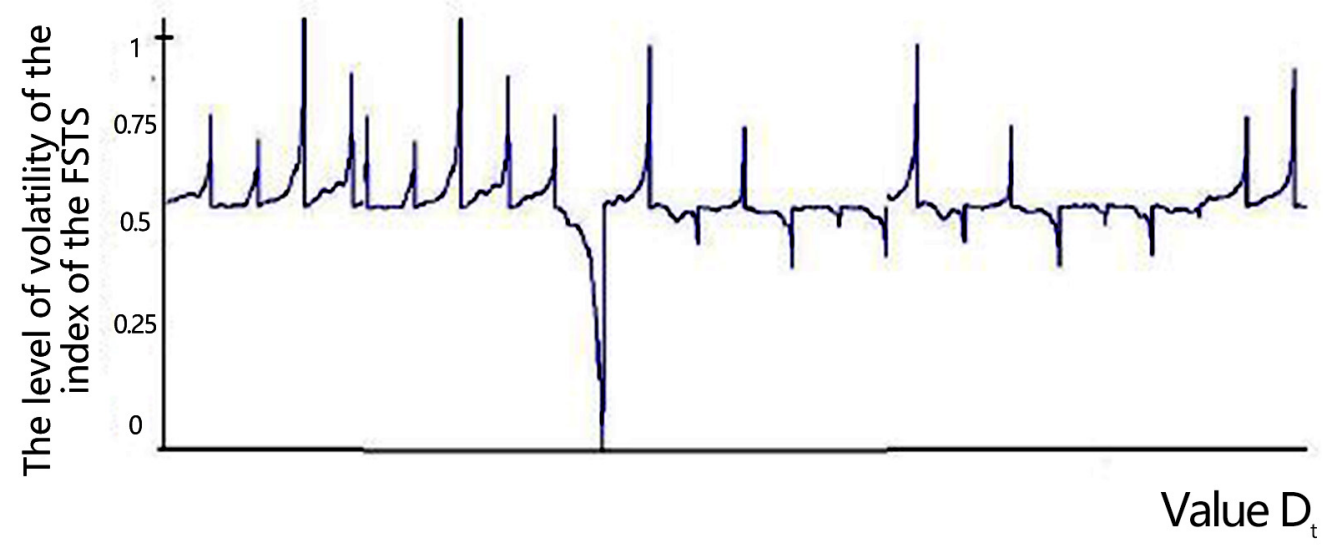

Figure 6. The volatility trend of the FSTS index in 2019 was found by the method of least squares

Using the model of dependent volatility, at rend $\mathrm{D}_{t}$ was constructed and the volatility of the FSTS index was found by its values, using the least squares method (LSM) (Figure 6). This process is best represented by a quadratic model (31):

$$
\sigma=a+b D_{t}+c D_{t}^{2}
$$

where: $\lambda=10, \tau=0.5, \mathrm{~N}=2000$. Estimates are obtained with an accuracy of 0.94 . The authors note also that the dependence of volatility, which includes information about the past, is allowed in a stable market, to predict the behavior of investors, as well as to reflect the positive or negative trends in assets.

Unlike standard local or stochastic volatility models, in the event of a sudden market crash, the dependent volatility model is designed to automatically increase its level in order to study market dynamics in a more natural way. That is, in this model, volatility does not need to be constantly adjusted (which is a disadvantage of local models of volatility).

\section{Sustainable Development of the Derivatives Market}

In formulating the sustainable development of the derivatives market, all its semantic and financial features take into account the resistance to external and internal factors (shocks, imbalances) and maintain dynamic equilibrium to ensure the parameters of the entire financial system needed to form positive feedback between the financial and real sectors of economy. However, during bifurcations in the financial system there is an increase in uncertainty and frequency of fluctuations, a sharp increase in variation of parameters that bring it out of equilibrium. Denoting the natural process of development of economic 
systems which is embodied in the violation of its balance and acting as elements of self-regulation, provides the restoration of balance at a qualitatively different level of a constructive or destructive nature. Thus, with regard to the banking sector, a crisis is a situation when at least one of the following conditions is met: the share of overdue debt in bank assets reaches $10 \%$; the cost of restoring the banking system exceeds $2 \%$ of Gross Domestic Product (GDP); more than $10 \%$ of the banks have been nationalized; a moratorium on the payment of deposits is imposed; there is panic among depositors [44; 45].

The derivatives market is developing with a limited base of crises, which provides macroeconomic stabilization in the country. Thus, during 2010-2019, the average value of the excess of the nominal value of derivative financial instruments over world GDP was 5.6 times. The highest value reached 13.8 times in the crisis of 2014.

This indicated the crossing of a certain limit of maximum imbalance between the needs of the real sector of the economy in risk management and speculative motives of the financial market with the vector of movement to the crisis (Figure 7). The authors believe that the economic system (including banking) develops in a stable way according to a certain parameter, if the deviation of this parameter does not exceed the allowable value, and obstacles can be compensated within certain limits. Moreover, the stability limit is a system of parameters, the transition beyond which leads the system from steady state to unstable one.

The authors believe that the margin of sustainability (bifurcation point) of the market of derivative financial instruments (DFI) is defined as a critical condition in which the risks of market participants hedged by DFI are not balanced with the risks arising in the process of speculation with them. At the same time, there may be a predominance of excess liquidity in the DFI market that is not related to the needs of the real sector of the economy, which ultimately leads to an increase in systemic risk and the realization of crises.

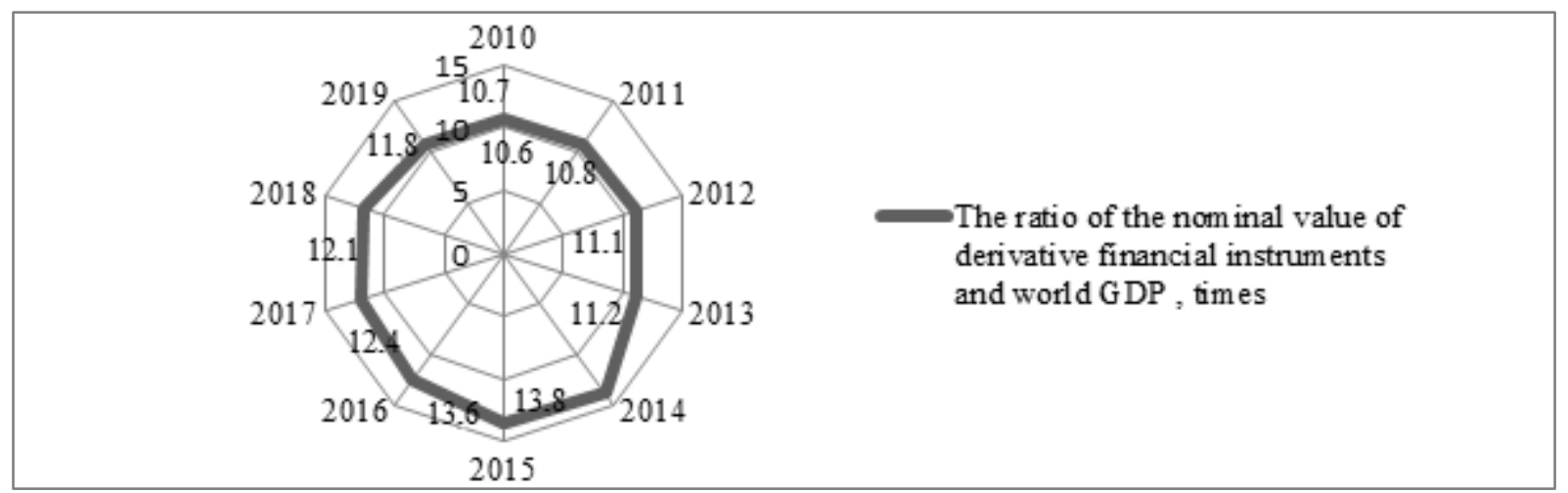

Figure 7. The ratio of the nominal value of derivative financial instruments and world GDP for the period of 2010-2019, times [36; 46].

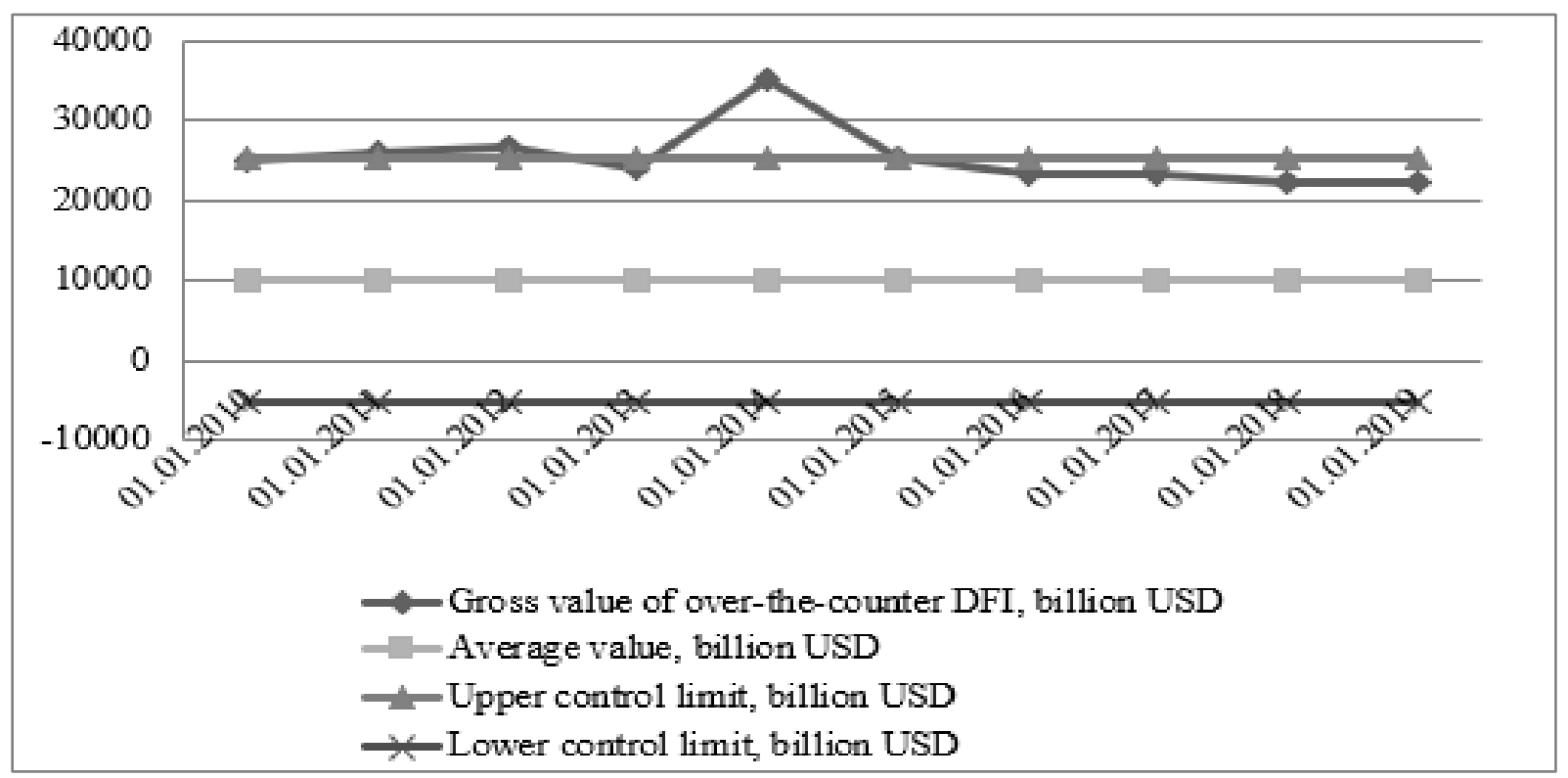

Figure 8. Map of gross market value of over-the-counter DFI for 2010-2019, billion USD [44; 46]. 
The limit period in the development of the DFI market is 2014 as the year of inflating the mortgage bubble and the accumulation of a critical mass of preconditions (the number of risks, including systemic, excess liquidity by market participants) before the crisis in 2015-2016. Figure 8 shows the average value and two control limits of the change in the gross market value of over-the-counter DFI during 2010-2019. The upper control limit is equal to the mean value, plus 3 standard deviations $(\sigma)$, and the lower control limit - the average value, minus $3 \sigma$. If the values of the studied process do not exceed the established control limits $(+/-3 \sigma)$, then with a probability of $99.73 \%$ this process can be considered stable and manageable.

If the graph is located within $(+/-2 \sigma)$, i.e., within the so-called warning limits, then the manageability of the system (process) can be said with probability- $95.46 \%$. An in-depth analysis of the obtained graphs can not only diagnose deviations in the current moment that appeared in the process, in this case - the dynamics of both over-the-counter and exchange market DFI, but also have a certain predictive direction for such deviations in the future and offer an opportunity to adjust the parameters of the system from the outside, if it is not capable of self-correction. Thus, getting 2 of 3 consecutive points (observations) in the zone of deviations 2-3 of the sigma (points for the period 31.12.2014-30.06.2015) or going beyond it can be perceived as an early warning of future deviations (crisis phenomena) in the process. It should be noted that the probability of error according to this criterion (the criterion is met, but the process does not go beyond the steady state) is $2 \%$. According to the above statistical methodology and calculations and graphical analysis, the authors can talk about the presence of the over-the-counter DFI market in the period $30.09 .2015-30.06 .2016$ with a probability of $99.73 \%$ in a state of crisis.

This period is the peak of the global financial crisis, which was accompanied by the maximum value of DFI in the over-the-counter market 35280 billion USD, bankruptcies of leading financial intermediaries and a significant increase in volatility not only in the DFI markets, but also in the underlying asset markets and in the real sector of the economy. The schedule the authors have built began to signal the probable occurrence of a market crisis in accordance with the established criteria in the second half of 2014, when the negative phenomena in the US mortgage market only began to be recorded. A similar situation can be observed with the dynamics of risk appetite in the over-the-counter DFI market (Figure 9), which also indicates the crisis of the over-the-counter DFI market, especially during the global financial crisis. For comparability and comparison, the authors built a control map for the indicator that characterizes the development of the exchange-traded DFI market (Figure 1).

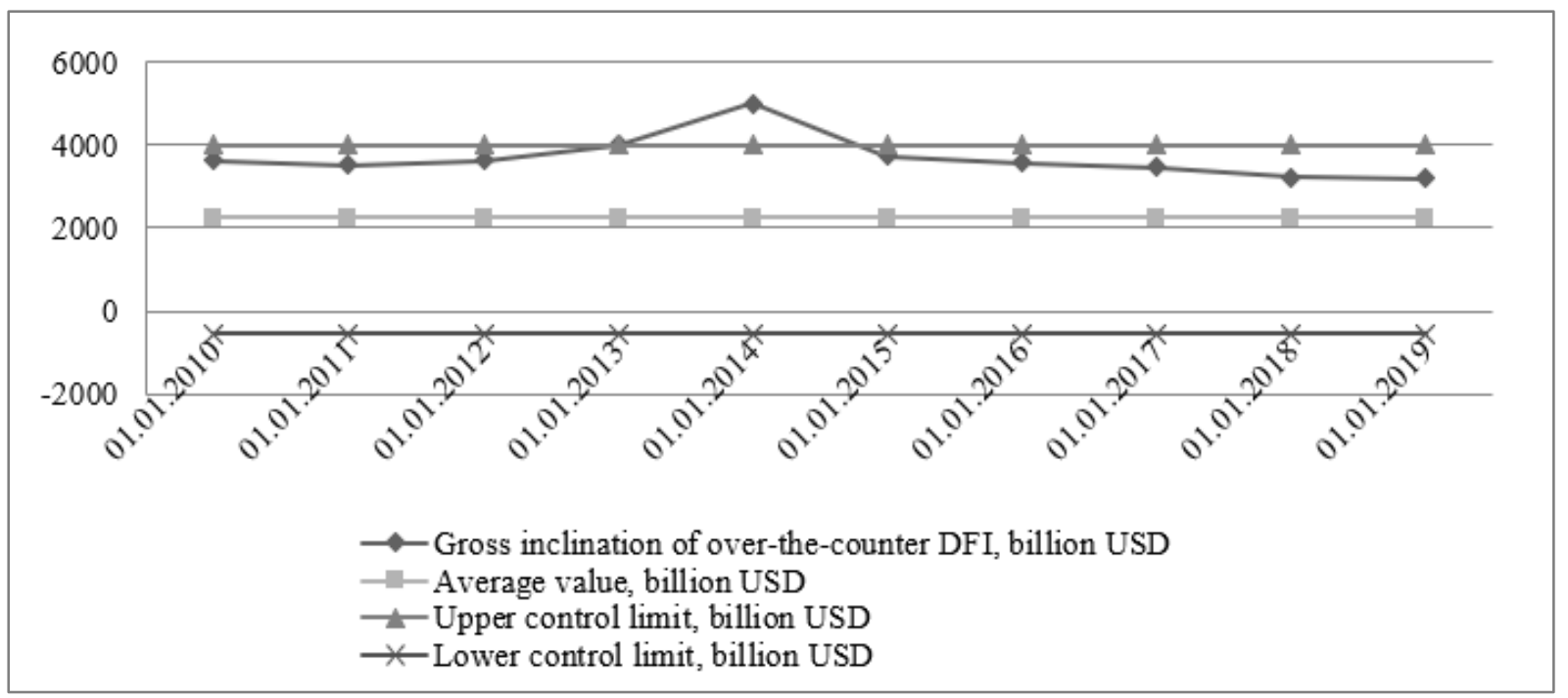

Figure 9. Map of gross risk exposure in the over-the-counter DFI market for 2010-2019, billion USD [36; 46] 


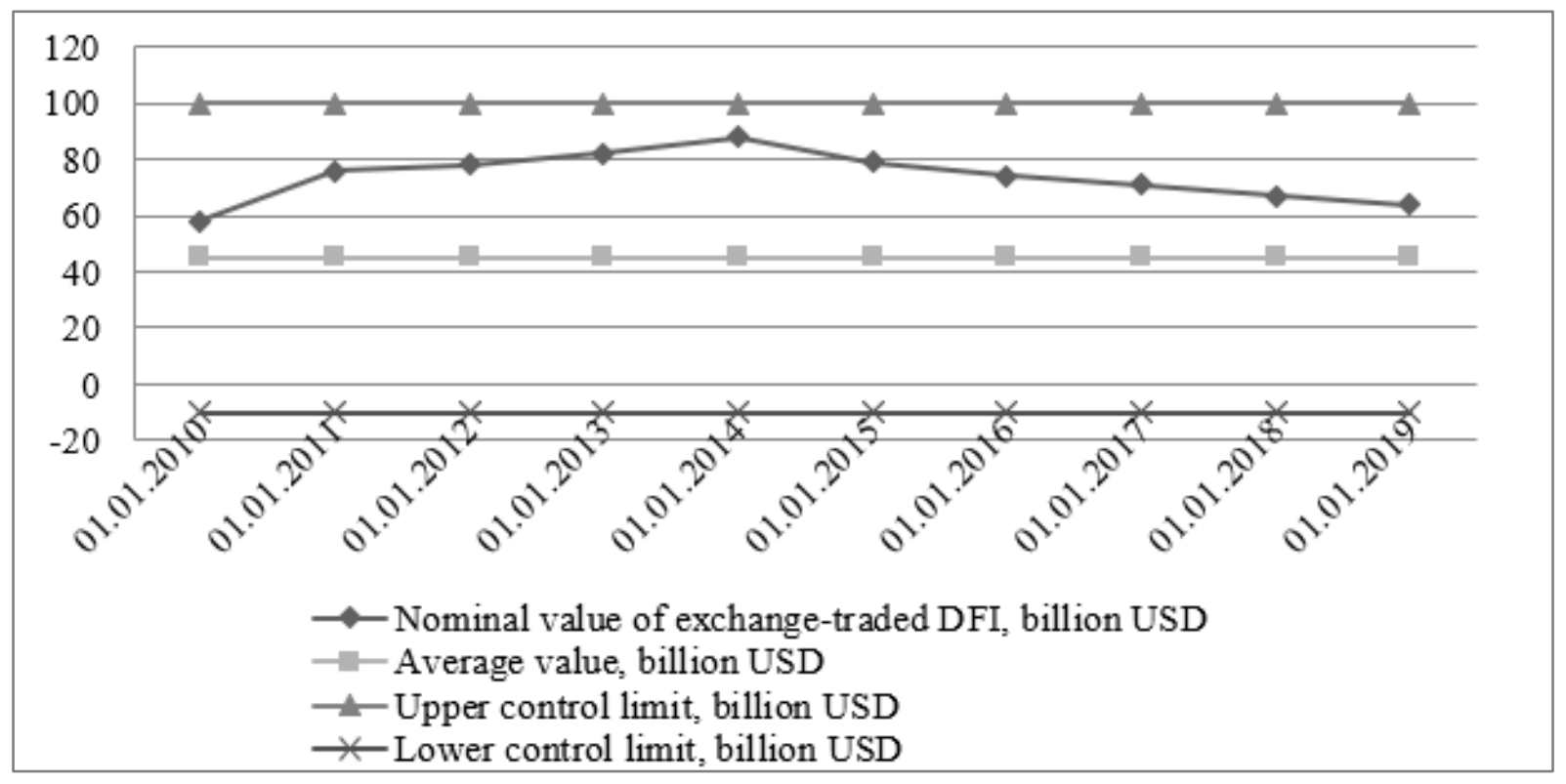

Figure 10. Map of the nominal value of exchange-traded DFI for 2010-2019, billion USD [36; 46].

In contrast to the over-the-counter market, the DFI exchange market is in a more stable, controlled state. The growth of deviations of the nominal value of exchange-traded DFI from their average value in 2014 - at the beginning of 2015 did not exceed the critical limit, even during the financial crisis, and, in addition, is a statistical justification for the need to converge stock exchange and over-the-counter markets and strengthen regulation of the latter at both national and global levels.

However, given the scale of the global over-the-counter DFI market and its dominance over the stock exchange market, the conclusions of the crisis in the DFI market during the global financial instability of 2014-2016 can be extrapolated to the entire DFI market as a whole. The confirmation of the crisis in the DFI market during the global financial crisis and the reliability of the rapid assessment obtained from Schuhart's maps is also the use of Irwin's method as a statistical method of checking the homogeneity of a series of dynamics, which detects and eliminates abnormal values of series levels data, the possibility of their comparison and stability (stationary). Irwin's method involves the use of the following formula (32) [45]:

$$
\lambda=\frac{\left|y_{t}-y_{t-1}\right|}{\sigma_{y}}, t=2,3, \ldots, n
$$

where: $\mathrm{y}_{t}-$ the level of a series of dynamics; $\sigma_{y}-$ standard deviation of a series of dynamics.

The calculated values $\lambda \_2, \quad \lambda \_3, \ldots, \lambda \_(n-1), \quad$ are compared with the critical value of the Irwin's criteria $\lambda \_$, and if they are greater than the critical value, the corresponding value of the series is considered anomalous. The level of significance is usually taken $\alpha=0.05$ [46]. Given the reliability and quality of the studied data on gross market value and gross risk appetite in the over-the-counter DFI market and the nominal value of exchange-traded DFI, the authors excluded the possibility of errors of the first kind by the Irwin method. As a result of its application, with the accepted level of significance $\alpha=0.05$, the number of observations $t=25$ and $\alpha=1.3$ for the date of 31.12 .2015 , the values of a number of gross market value and gross risk appetite were abnormal, in that while for the nominal value of exchange-traded DFI, this value was typical (Table 2). The residual impact of the crisis is observed on 30.06.2016 and is approaching abnormal. Thus, these anomalous values are objective in nature, indicating a sharp change in the patterns of development of the DFI market and the emergence of a crisis in the over-the-counter DFI market, which compared to the stock exchange market, is less regulated and riskier.

Table 2. Series of dynamics of the DFI market (by the method of Irwin)

\begin{tabular}{|c|c|c|c|}
\hline \multirow{2}{*}{ Indicator } & Date & $\begin{array}{c}\text { Actual } \\
\text { value, } \\
\text { billion USD }\end{array}$ & $\begin{array}{c}\text { Abnormal } \\
\text { (estimated } \\
\text { value) }\end{array}$ \\
\hline $\begin{array}{c}\text { Gross value of } \\
\text { over-the-counter } \\
\text { DFI }\end{array}$ & 31.12 .2014 & 35280 & 1.71 \\
\cline { 2 - 4 } & 30.06 .2015 & 25310 & 1.14 \\
\hline $\begin{array}{c}\text { Gross inclination of } \\
\text { over-the-counter } \\
\text { DFI }\end{array}$ & 31.12 .2014 & 5010 & 1.43 \\
\cline { 2 - 4 } & 30.06 .2015 & 3740 & 1.14 \\
\hline $\begin{array}{c}\text { Nominal value of } \\
\text { exchange-traded DFI }\end{array}$ & 31.12 .2014 & 79 & 0.89 \\
\hline
\end{tabular}

Thus, the scale of the DFI market in the process of macroeconomic stabilization is key to the safe functioning of global and national financial systems. Considering the DFI market as a complex, open dynamic system from the standpoint of a systems approach, its inability to self-regulate and maintain sustainable development should be emphasized. This is demonstrated by the rapid assessment of his condition based on Schuhart's control 
maps and Irwin's method. Their approbation showed that only the DFI exchange market showed signs of self-organization and self-regulation.

To verify the quantitative impact of factors on the development of the DFI market (level of systemic risk, market risks, level of bank advantage, hedge funds, macroeconomic parameters, the scale of the financial system) used formalized models of multicollinearity within the global and national levels. When constructing regression models simultaneously, two correlation matrices are formed. The equation did not include variables, the correlation coefficient between which is greater than 0.8 . In particular, in the array of data on the stock exchange and over-the-counter DFI market, among such factors we excluded global financial market indices (NASDAQ, Nikkei 225, DLA, FTSE 100, performance indicators of banks, hedge funds, CPI), which closely correlate with other factors.

Regarding the Ukrainian market, the following factors determine the factors of the stock market: the volume of registered and executed transactions with securities, the volume of issues of shares and bonds; money market indicators: money supply and money base; indicators of the banking system: assets, liabilities, equity of banks, interest spread. The correlation of all these factors is explained by their economic content and a certain ratio. Thus, world stock indices clearly reflect all the trends of macroeconomic indicators, as well as stock market indicators, which are linearly dependent on the state of the economy. Based on the selected factors, multifactor regression models were built (Table 3 ).

The given coefficients of determinationR 2 for each of the models indicate the existence of a tight and very tight relationship $(0.7 \leq \mathrm{R} 2 \leq 0.9 ; \mathrm{R} 2 \geq 0.9)$ between the studied factors and the nominal value of DFI. The significance of these coefficients and, accordingly, the adequacy of the models is confirmed by the significance of the F-criterion - for each of the models its value does not exceed 0.05 (with the established confidence probability 95\%). The significance of the obtained coefficients of variables in the models is confirmed by the t-criterion. Regression models have been developed in terms of the influence of a group of financial sector factors (money market, foreign and domestic stock market and banks) on the Ukrainian DFI market (Table 4).

Table 3. Regression models of the influence of factors on the development of the global exchange and over-the-counter DFI market

\begin{tabular}{|c|c|c|c|c|}
\hline \multirow{2}{*}{$\begin{array}{c}\text { Group } \\
\text { of factors }\end{array}$} & \multicolumn{2}{|l|}{ Over-the-counter DFI market } & \multicolumn{2}{|l|}{ DFI exchange market } \\
\hline & Type of model & $\mathbf{R}^{2}$ & Type of model & $\mathbf{R}^{2}$ \\
\hline $\begin{array}{l}\text { Market } \\
\text { participants - } \\
\text { banks }\end{array}$ & $\begin{array}{l}Y=0.225 L R / A^{1}-0.729 B L R- \\
-0.217 C / A R+0.183 D C / G D P\end{array}$ & 0.84 & $\begin{array}{l}Y=0.476 L R / A-0.533 B L R- \\
-0.192 C / A R+0.028 D C / G D P\end{array}$ & 0.88 \\
\hline $\begin{array}{c}\text { Market } \\
\text { participants - } \\
\text { hedge funds }\end{array}$ & $\begin{array}{l}Y=0.319 G H F I+1.001 F H F A+0.335 H F A R- \\
-0.169 H F L R+0.092 H F N A\end{array}$ & 0.97 & $\begin{array}{l}Y=0.299 G H F I+1.046 F H F A+0.212 H F A R- \\
-0.123 H F L R+0.098 H F N A\end{array}$ & 0.97 \\
\hline $\begin{array}{l}\text { State of the } \\
\text { economy }\end{array}$ & $\begin{array}{l}Y=-0.319 H F D I+0.639 H F P I- \\
-0.728 G D P c h+0.8 I N F\end{array}$ & 0.93 & $\begin{array}{l}Y=-0.372 H F D I+0.791 H F P I- \\
-0.540 G D P c h+0.667 I N F\end{array}$ & 0.88 \\
\hline $\begin{array}{l}\text { State of the } \\
\text { financial } \\
\text { system }\end{array}$ & $\begin{array}{l}Y=0.263 M C L C+0.620 S h T R- \\
-0.296 M 2 / G D P\end{array}$ & 0.95 & $\begin{array}{l}Y=0.427 M C L C+0.367 S h T R- \\
-0.401 M 2 / G D P\end{array}$ & 0.96 \\
\hline
\end{tabular}

Note: LR/A - the ratio of liquid reserves to assets; BLR - level of leverage of banks, times; C/AR - capital to assets ratio - capital adequacy, \%; DC/GDP - domestic loans of the banking sector, in \% of GDP; GHFI - average annual return on hedge funds, \%; FHFA - fund assets for hedge funds, billion USD; HFAR - reduction factor, \%; HFLR - level of hedge fund leverage, \%; HFNA - net assets of hedge funds, billion USD; NFDI - net foreign direct investment flow, billion USD; NFPI - net portfolio investment flow, billion USD; GDPch - annual GDP growth, \%; INF - GDP deflator, \%; MCLC market capitalization of listed companies on the exchange market, billion USD; ShTR - stock turnover ratio, \%; M2/GDP - depth of the financial sector, \%.

Table 4. Regression models of the influence of factors on the development of national DFI market

\begin{tabular}{|c|c|c|}
\hline Group of factors & Type of model & $\mathbf{R}^{\mathbf{2}}$ \\
\hline Market participants - banks & $Y=-0.081 B L R+0.631 N L / G L^{1}-0.964 C / A R$ & 0.75 \\
\hline Market participants - hedge funds & $Y=0.023 D R-0.299$ CERDOL & 0.97 \\
\hline State of the economy & $Y=-0.858 M T R-1.088 G D P+0.063$ INF & 0.93 \\
\hline State of the financial system & $Y=-0.154 M C L C-0.327$ ShTV $-0.660 M 2 / G D P$ & 0.95 \\
\hline
\end{tabular}

Note. NL/GL - the ratio of non-performing (overdue) loans to their total number, \%; DR - discount rate of the NBU (at the end of the period), \%; CERDOL - official exchange rate of hryvnia against the US dollar, average for the period, UAH; MTR - marginal corporate tax rate, \%; GDP - GDP at actual prices, million UAH; FCM - financing through capital markets, gross flow; GEI - is the global capital index of S\&P. 
Thus, the statistical assessment of the nominal value of options in the DFI market of Ukraine indicates the existence of a medium-strength relationship with money and foreign stock markets, as well as with the real sector of the economy $(0.5 \leq \mathrm{R} 2 \leq 0.7)$ and tight $(\mathrm{R} 2 \geq 0.7)$ relationship with all other groups. Thus, the calculated criteria of $\mathrm{F}$ and $\mathrm{t}$-statistics indicate the insignificance of the coefficient of determination and the unreliability of the established relationships between the studied variables. This characterizes the incomplete formation of the financial market of Ukraine, i.e., there is insufficient liquidity in the market of underlying assets, spot market and at the national level the over-the-counter segment of DFI dominates.

The level of development of the global DFI market raises a number of prospects for strengthening the regulation of this market.

Along with this, the prospects for the development of the global DFI have the same directions in relation to the national market and are specified around the regulatory and infrastructural aspects. The regulation of the legal field of market functioning and conceptual bases of its development in the adapted market infrastructure, namely depository, clearing systems, liquidation netting and bankruptcy of market participants should have a platform of stable financial resources to support DFI operations, the amount of capital, liquidity, the risk management of market participants, as well as the taxation of DFI.

\section{Conclusions}

The analysis of the coefficients of regression equations for the sustainable development of the stock exchange and over-the-counter DFI market allowed drawing the following conclusions. Thus, capital adequacy, the level of leverage of banks and hedge funds in accordance with the negative values of the ratios of these variables affect the state of the market in reverse. The increase in leverage levels as the ratio of borrowed funds to the own financial resources of individual DFI market participants leads to a crisis in the financial system due to the self-reinforcing leverage effect and the deployment of a pro-cyclical spiral.

At the same time, the low capital adequacy of banks, compared with significant amounts of financial assets focused on the balance sheet of banks, as a result of speculative trade in DFI at their own expense (proprietary trading). The securitization of assets and the issuance of DFI on these assets results from the desire of banks to reduce the amount of regulatory capital and promote credit expansion and maintaining profits. These actions of banks took place in conditions of high moral hazards associated with underestimation of the risk of borrowers, which led to an increase in DFI in the market and the violation of its sustainable state of development.
It should be noted that from the point of view of a systematic approach, the DFI market has moved to the level of self-organization. In terms of its cyclical nature, it is immanent in relation to other segments of the financial market in the modern world economic space. However, given the size of the DFI market and its repercussions on underlying asset markets, there is a likelihood of a threat to the entire real sector of the economy, which requires measures to predict and prevent DFI volatility through financial instruments and regulators of the financial system as a whole.

\section{REFERENCES}

[1] R. De Ayadi, W. P. Groen, I. Sassi, W. Mathlouthi, H. Rey, O. Aurby. Banking business models monitor 2015: Europe, 2016, Online available from https://www.ceps.eu/download/publication/?id=9236\&pdf =Banking-Business-Models-Monitor-Europe-2015.pdf.

[2] H. H. Cao. The effect of derivatives assets on information acquisition and price behavior in rational expectation equilibrium model, The Review of Financial Studies, Vol. 12, No. 1, 131-163, 1999.

[3] D. Chance. Essays in Derivatives: Risk-Transfer Tools and Topics Made Easy, John Wiley, New York, 2008.

[4] A. Chisholm. Derivatives Demystified: A Step-By-Step Guide to Forwards, Futures, Swaps and Options, John Wiley \& Sons, New-York, 2004.

[5] M. R. Darby. Over-the-counter derivatives and systemic risk to the global financial system, Advances in International Banking and Finance, Vol. 3, No. 1, 215-235, 1997.

[6] R. Davies, Gambling on derivatives hedging risk or courting disaster? 2002, Online available from https://projects.exeter.ac.uk/RDavies/arian/scandals/derivat ives.html.

[7] D. Duffie, A. Li, Th. Lubke. Policy Perspectives on OTC derivatives market infrastructure: Staff report, Federal Reserve Bank of New York, 2010, Online available from https://www.newyorkfed.org/research/staff reports/sr424.h tml

[8] R. Ferstl, D. Seres. Clustering Austrian banks' business models and Peer Groups in the European banking sector, Financial Stability Report, Vol. 24, 79-95, 2012.

[9] J. B. Foster. Financialization of capitalism, John Bellamy Foster, Vol. 11, 8-10, 2007.

[10] J. A. Frankel, A. K. Rose. Currency crashes in emerging markets: Empirical indicators, NBER Working Paper, 1996, Online available from https://www.nber.org/papers/w5437

[11] H. Jo, C. Lee, A. Munguia, C. Nguyen, Unethical misuse of derivatives and market volatility around the global financial crisis, Journal of Academic and Business Ethics, 2013, Online available from https://www.aabri.com/manuscripts/09398.pdf 
[12] J. C. Hull. Options, Futures and Other Derivatives: Sixth Edition, Prentice Hall, New Jersey, 2006.

[13] A. A. Litvinova. Regulatory approach to derivative markets: The benefits of private sector oversight, 2007, Online available from http://digitalcommons.pace.edu/honorscollege theses/47.

[14] G. C. Nwaovi. The economics of financial derivative instruments, MPRA Paper, 2008, Online available from http://mpra.ub.uni-muenchen.de/9463/.

[15] M. Rubinstein. Derivatives: Futures, Options and Dynamic Strategies. Risk Books, IL, Chicago, 1999.

[16] G. L. Kaminsky, C. M. Reinhart. The twin crises: The causes of banking and balance-of-payments, American Economic Review, Vol. 89, No. 3, 473-500, 1999.

[17] L. Laeven, F. Valencia. Systemic Banking Crisis: A new database. IMF Working Papers, 2008, Online available from

https://www.imf.org/en/Publications/WP/Issues/2016/12/3

1/Systemic-Banking-Crises-A-New-Database-22345

[18] A. Demirguc-Kunt, E. Detragiache. The determinants of banking crises in developing and developed countries, International Monetary Fund, Vol. 45, No. 1, 81-109, 1998.

[19] A. Demirguc-Kunt, E. Detragiache. Cross-country empirical studies of systemic bank distress: A survey, 2005, Online available from https://openknowledge.worldbank.org/handle/10986/8266

[20] I. Britchenko, T. Cherniavska. Blockchain technology in the fiscal process of Ukraine optimization, Ikonomicheski Izsledvania, Vol. 28, No. 5, 134-147, 2019.

[21] P. Carr, V. Linetsky. A jump to default extended CEV model: An application of Bessel processes, Finance and Stochastics, Vol. 10, No. 3, 303-330, 2006.

[22] M. Rubinstein. Rational markets: Yes or no? The affirmative case, Financial Analysts Journal, Vol. 57, No. 3, 15-29, 2001.

[23] M. Schroder. Computing the constant elasticity of variance option pricing formula, Journal of Finance, Vol. 44, 211-219, 1989.

[24] J. C. Cox, S. Ross, M. Rubinstein. The Valuation of options for alternative stochastic processes, Journal of Financial economics, Vol. 3, 145-166, 1976.

[25] M. Jeanblanc, M. Yor, M. Chesney. Mathematical Methods for financial Markets, Springer Verlag, Berlin, 2009.

[26] D. Madiyarova, R. Abdrakhmanova. Socioeconomic effects of integration actions (the study case of the customs union), Actual Problems of Economics, Vol. 135, No. 9, 393-401, 2012.

[27] E. M. Akhmetshin, D. K. Dzhavatov, E. A. Sverdlikova, M. S. Sokolov, O. A. Avdeeva, G. P. Yavkin. The influence of innovation on social and economic development of the Russian Regions, European Research Studies Journal, Vol. 21, Special Issue 2, 767-776, 2018.

[28] E. I. Makhnitskaya, U. Z. Shalbolova. Regional model of investment innovative processes development, Actual Problems of Economics, Vol. 133, No. 7, 414-426, 2012.
[29] U. Z. Shalbolova, S. M. Yegemberdiyeva, S. S. Uderbayev, M. A. Elpanova, L. A. Kazbekova. Specifics of oil pipeline systems' risks management, Life Science Journal, Vol. 11, No. 11, 591-594, 2014.

[30] D. G. Hobson, L. G. Rogers. Complete models with stochastic volatility, Mathematical Finance, Vol. 8, 27-48, 1998.

[31] I. V. Burtnyak, G. P. Malytska. Volatility modeling for the PFTS index using the generalized Hobson-Rogers model, Modeling of the Regional Economy, Vol. 2, 446-452, 2015.

[32] B. Derevyanko, Y. Zozulia, L. Rudenko. Money assets of internally displaced persons as financial resources of commercial banks, Banks and Bank Systems, Vol. 12, No. 4, 211-217, 2017.

[33] G. F. Galiullina, R. R. Aetdinova, L. R. Sharipova. Managment model of administrating territories with special entrepreneurial treatment, Journal of Environmental Treatment Techniques, Vol. 7, Special Issue, 950-954, 2019.

[34] A. A. Zhigir. Financial and credit instruments of activation of environmental entrepreneurship in the agrarian sphere, IOP Conf. Series: Earth and Environmental Science, Vol. 677, 022061, 2021.

[35] Quarterly Reviews, Online available from https://www.bis.org/quarterlyreviews/index.htm.

[36] A. A. Kartskhiya, S. A. Tyrtychnyy, M. G. Smirnov, M. G. Dolgikh, L. A. Khmelnitskiy. Digital technologies in supply chain management for production and digital economy development, International Journal of Supply Chain Management, Vol. 9, No. 3, 912-918, 2020.

[37] V. V. Shlychkov, I. K. Kiyamov, A. S. Khasanova, S. M. Kulish, D. R. Nestulaeva. Hands-on management: Theoretical and methodological approaches and Russian practice of state and municipal management, European Research Studies Journal, Vol. 20, No. 2, 200-223, 2017.

[38] D. Madiyarova, A. Amirbekova, M. Syrlybayev. Comparative advantages of Kazakhstan assessed by the Balassa Index: Consistently competitive exports are limited to raw materials with low added value, Journal of Business and Retail Management Research, Vol. 12, No. 3, 201-210, 2018.

[39] I. V. Burtnyak, G. P. Malytska. Investigation of volatility by means of modification of the Black-Scholes model, Business Inform, Vol. 5, No. 1, 72-75, 2011.

[40] A. Shakbutova, A. Saparbayev, P. Stanislaw, A. Makulova, A. Nurmukhan. Impact of tax competition on fiscal incomes of Kazakhstan in terms of tax competitive environment, E3S Web of Conferences, Vol. 159, 06006, 2020.

[41] S. Mishchenko, S. Naumenkova, V. Mishchenko, D. Dorofeiev. Innovation risk management in financial institutions, Investment Management and Financial Innovations, Vol. 18, No. 1, 191-203, 2021.

[42] G. Galiullina. The evolution model of territories of advanced development based on the institutional-synergetic approach, E3S Web of Conferences, Vol. 208, 08028, 2020.

[43] R. Kumar. Effect of volatility clustering on indifference pricing of options by convex risk measures, Applied 
Mathematical Finance, Vol. 22, No. 1, 63-82, 2015.

[44] B. Kyshakevych, I. Klymkovych. Estimation of Z-score for Ukrainian banking system, Scientific Journal of Polonia University, Vol. 30, 43-51, 2018.

[45] Compilation Guide on Financial Soundness Indicators,
2012, Online available from https://www.imf.org/external/ $\mathrm{np} / \mathrm{sta} / \mathrm{fsi} / \mathrm{eng} /$ guide/index.htm.

[46] T. Bollerslev, R. F. Engle. Common persistence in conditional variances, Econometrica, Vol. 61, 167-186, 1993. 